\title{
The static and fatigue response of metal laminate and hybrid fibre-metal laminate doublers joints under tension loading
}

\author{
S. Sugiman ${ }^{a}$, A.D. Crocombe ${ }^{b, *}$ \\ ${ }^{a}$ Department of Mechanical Engineering, Faculty of Engineering, University of Mataram, Mataram, West \\ Nusa Tenggara, 83125, Indonesia. \\ ${ }^{\mathrm{b}}$ Division of Mechanical, Medical and Aerospace Engineering, Faculty of Engineering and Physical \\ Sciences, University of Surrey, Guildford, Surrey, GU2 7XH, UK.
}

\begin{abstract}
Experimental and numerical studies have been undertaken on metal laminate (ML) doublers and hybrid fibre-metal (aluminium-Glare) laminate (FML) doublers to investigate their static and fatigue response under tension loading. Inevitably sheets in these laminates butt together and these butts can affect the joint strength. Progressive damage modelling, including the damage in the adhesive bondline, the butt, the metal and the fibre has been undertaken in both static and fatigue loading. This modelling was found to be in good agreement with the experiment data in terms both of the strength and the failure mechanisms. In ML, the butt influenced the static and fatigue response. In hybrid FML, the specimens either have the fibres parallel to the loading direction (spanwise) or perpendicular to the loading direction (chordwise). The spanwise specimen was found to have the highest strength followed by chordwise specimens without butts and finally chordwise specimens with butts. The most critical position for a butt was found to be adjacent to the doublers end. Without butts the static strength for spanwise and chordwise specimens was controlled by the failure in the Glare layer whilst the fatigue failure was precipitated by failure in the aluminium sheet.
\end{abstract}

Keywords: Metal laminate, Aluminium, Glare, Numerical analysis, Strength, Failure mechanisms.

* Corresponding author. Phone: +44 1483 689194, Email address: a.crocombe@ surrey.ac.uk 


\section{Introduction}

Monolithic aluminium alloy plates have been widely used in aircraft structures over many years. However monolithic aluminium is prone to fatigue failure especially in (tensile) lower wing structures. In monolithic aluminium, once the surface crack has initiated this accelerates leading to the premature failure. This has been a concern to the aircraft industry for many years. Realising this problem, Schliekelmann [1] used laminated aluminium on the Fokker wing structure which improved the fatigue performance. Schijve et al. [2] used aluminium laminates on a large wing joint and explored their fatigue properties. The finding was surprising, because the crack growth was extremely slow. The crack initiated in the outer layer and the other layers bridged the crack, slowing down the propagation.

Further developments involved using combined aluminium-composite laminates (such as Glare) in the aircraft fuselage (i.e in Airbus A320 fuselage). This saved up to $25 \%$ weight in the fuselage and was even more promising [3]. Glare has much better fatigue performance than the monolithic aluminium. The best fatigue performance of Glare is obtained with the fibres running along the loading direction due to better fatigue performance of the fibre in that direction [4]. The improved crack resistance of Glare compared with monolithic aluminium is attributed to the unbroken fibre layers which bridge the crack in the aluminium [5, 6]. Other advantages of using Glare beside the weight saving and fatigue insensitivity is high impact resistance, corrosion resistance, flame resistance [7], excellent damage tolerance [8] and production simplification [9].

Large skin Glare sheets are required to manufacture a wing panel or body fuselage to reduce the amount of joints. Currently aluminium sheets with a maximum width of $1.60 \mathrm{~m}$ can be manufactured [10]. The other limiting factors on producing large panels are pre- 
treatment, autoclave curing, and C-scan facilities. A design concept has been developed to overcome the joining problem and is termed the splice. The original spliced concept consisted of butted aluminium with the fibre layer bridging the splices (butts). However, this "butt splice" was found to be an unacceptable joining technique with early failure in the butts. Different designs of splice were assessed and finally a concept of an "overlap splice" was developed where the aluminium layers overlapped each other and were adhesively bonded [11]. The thick, large panel of a wing cover can be manufactured by incorporating Glare layers into a metal laminate. This can be done by replacing selected aluminium layers in the metal laminate with Glare layers.

Predictive model to simulate the damage in the adhesive layer of a bonded structure under static and fatigue loading using a bilinear traction-separation law has been reported in the literature [12-21]. Numerical studies on the static and fatigue response using continuum damage for fiber [22-26] and for ductile metal [27-35] have also been reported. However, most of the studies focused on single material failure rather than multiple material failure that will occur in ML and FML structures.

In wing structures, a local reinforcement (stringer) is bonded on the wing skins to increase their stiffness. In addition, the stringer can compensate for the reduction of strength of the laminates due to the butt in either the aluminium or the Glare layers. However, the bonded stringer creates local bending when it subjected to tension load [36] and this can affect the mechanical response, particularly when the laminate contains butts adjacent to the edge of bonded stringer. In this paper the mechanical response of ML and hybrid FML doublers joints under static and fatigue tensile loading are presented. One configuration of ML and four configuration of FML were considered. As the ML and Glare were provided "as 
manufactured" it was not possible to assess more complex forms of butting and Glare sheet splicing. The configurations were determined by Airbus and considered appropriate for a preliminary testing programme. The specimens have been subjected to static and fatigue tension loads and the failure behaviour for each joint has been determined. Progressive damage finite element modelling (FEM) has also been undertaken to predict the static and fatigue response and failure mechanisms observed.

\section{Materials and Experimental Methods}

\subsection{Metal laminate doublers (ML)}

The metal laminate was made of aluminium 2024-T3 bonded using film adhesive FM 73M (with mat carrier) from Cytec [37]. The laminate consisted of 6 layers of aluminium and 5 layers of adhesive, with thicknesses of approximately $1.6 \mathrm{~mm}$ and $0.15 \mathrm{~mm}$ respectively. Prior to bonding, the aluminium surfaces were treated using chromic acid etching (CAE) followed by phosphoric acid anodising (PAA) and then primering using BR127 as recommended by the manufacturer [37]. Curing temperature for this laminate was $120^{\circ} \mathrm{C}$ for 1 hour, also as recommended [37]. The stringer bonded onto the laminate panel was aluminium 7055-T7751 using the same adhesive and surface treatment as the laminate. The length and the thickness of the stringers varied from 85-93 $\mathrm{mm}$ and 9.5-10.5 $\mathrm{mm}$ respectively. The thickness of the stringer adhesive layer was not constant along the length due to the curvature of the panel from which the specimens were cut. It was thinner at the edge (around $0.1 \mathrm{~mm}$ ) and thicker at the centre (around $0.2 \mathrm{~mm}$ ). The ML specimens (Fig. 1) contained discontinuities in the form of butts between adjacent co-planar aluminium sheets. The butt region was filled with the adhesive. 


\subsection{Hybrid FML}

The hybrid fibre-metal laminate (FML) specimens (Fig. 2) were supplied by Airbus (Bristol, UK). The hybrid was manufactured using an autoclave and consisted of 4 layers of aluminium 2024-T3 of thickness $1.65 \mathrm{~mm}$, and 2 layers Glare 2B of thickness $1.66 \mathrm{~mm}$. Aluminium and Glare layers were bonded using the same adhesive (with a woven carrier) with a resulting bondline thickness of $0.22 \mathrm{~mm}$. Glare $2 \mathrm{~B}$ consisted of 3 layers of aluminium (each with a measured layer thickness of $0.375 \mathrm{~mm}$ ) alternating with 2 layers of unidirectional S2 glass fibre/FM94 epoxy (GFRP) (with a thickness of $0.267 \mathrm{~mm}$ ). There were gaps where the Glare layers butt end to end and these were filled with the adhesive. Unfortunately, post-manufacture, it was realised that poor surface preparation of the aluminium sheets led to non optimal (weak) bonding between aluminium sheet and the Glare sheet. The surface treatment within the Glare and of the stringer onto the laminate, which were the more important bonds, was optimal.

Specimens were cut from a larger panel. There were two kinds of specimens according to the fibre and aluminium rolling direction. The first was spanwise specimens (SP), where the fibre and aluminium rolling direction ran along the specimen length, the second was chordwise specimens, where the fibre and aluminium rolling direction ran perpendicular to the specimen length. Some of the chordwise specimens contain two butts (between adjacent Glare layers). They were grouped as butt type-1 (CH-B1) and butt type-2 (CHB2) based on the location of the butts. In $\mathrm{CH}-\mathrm{B} 1$, the butts were located at non-critical locations (one butt inside the stringer and the other outside the stringer near the grip). In $\mathrm{CH}-\mathrm{B} 2$, the butts were located in the critical regions, (immediately under one of the stringer edges). The specimens without butts have been referred to as ( $\mathrm{CH}-\mathrm{NB})$. The dimension of the specimens were similar for all joint configurations, therefore, only $\mathrm{CH}$ - 
B1 and $\mathrm{CH}-\mathrm{B} 2$ have been shown in Fig. 2, to illustrate the location of the butts. The width of all specimens was $15 \mathrm{~mm}$. The configuration of specimens including the lay up of the laminate and butt positions were determined by Airbus.

\subsection{Mechanical testing}

The ML and hybrid FML doublers were loaded in tension in an Instron 1341 servohydraulic machine. The grip length was kept at $40 \mathrm{~mm}$ at both ends. The static tests were performed at a rate of $0.1 \mathrm{~mm} / \mathrm{min}$. The fatigue loading was sinusoidal with the maximum load level of either $60 \%$ or $50 \%$ of the static strength. The load ratio and the test frequency were 0.1 and $5 \mathrm{~Hz}$ respectively. Due to a limited number of specimens, only two replicates were tested, the results showed good consistency. Testing was carried out at room temperature $\left(20^{\circ} \mathrm{C}\right)$ in a laboratory environment. The failure process during the static and fatigue testing was monitored visually and using a video microscope connected to a computer.

\section{Experimental Results}

\subsection{Static response}

\section{a. Metal laminate doublers in tension}

The average static strength for the ML is $41.6 \pm 0.1 \mathrm{kN}$. To gain more understanding the failure of the ML is discussed in more detail below. The white circles with labels $\mathbf{1 - 5}$ as seen in Fig. 3a, represent the time when the images shown in Fig. 3b were taken. At point 1, when load reached $34 \mathrm{kN}$, the butt just inside the grip started to fail, preceded by the failure at the four corners of the butt. When the load increased, the damage in the butt grew further and the aluminium layer with the butt could not transfer and carry the load, therefore, the load was transferred to the surrounding layers, and increased the stresses in 
this region. At point 2 , at load $41 \mathrm{kN}$, the load-displacement response became flatter. The butt inside the grip failed completely and at the same time the stringer adhesive layer also showed damage. The load remained essentially constant up to point $\mathbf{3}$ due to yielding in the aluminium layers. The adhesive damage grew further until it reached a certain distance from the butt inside the stringer and it then grew faster and led to the failure of butt inside the stringer. This was indicated by the sudden load drop. It was then rapidly followed by the failure of the aluminium in the bottom layer near the outside butt, because in this region it was highly loaded due to lack of load transfer through the butt, and the load dropped further abruptly (point 4). The plateau curve where point 5 was located was the delamination process of the rest of aluminium layers, preventing load transfer from failed to adjacent intact aluminium layers.

\section{b. Hybrid FML doublers in tension}

The detail of experimental static response of the hybrid FML can be found elsewhere [38]. Only a summary of static response (see Fig. 4) and failure mechanism are presented. The highest to the lowest static strength of the hybrid FML is SP, CH-NB, CH-B1 and CH-B2 respectively. In the hybrid FML without butts, Glare failure controlled the static strength; however, when butts are present they control the static strength. All specimens responded linearly initially and the initial point of non-linearity is yielding of the aluminium. The SP cure is stiffest following this initial yield as the fibres are still responding in a linear manner. When the fibres fail the load drops suddenly. The long non-linear plateau in the CH-NB specimen is simply the yielding of the aluminium. The fibres are running transversely and the GFPR experiences matrix failure at an early stage. The $\mathrm{CH}-\mathrm{B} 2$ has the butts in a critical location and they fail very early effectively limiting the number of layers carrying the load. CH-B1 is similar but the butt fails a little later as it is not so critically 
located. A much more detailed description of the static failure in the FML specimens is given elsewhere [38]

\subsection{Fatigue response}

\section{a. Metal laminate doublers in tension}

Fig. 5 shows the load-life curve of the ML loaded in tension. A consistent fatigue life at the higher loads ( $27 \mathrm{kN}$ and $25 \mathrm{kN})$ was observed, however, at the lower load $(20 \mathrm{kN})$ the data showed more scatter. Inspection of the failed specimens with the lower fatigue lives at the $20 \mathrm{kN}$ load level revealed the existence of a flaw on the aluminium, right under the stringer edge.

The failed ML specimen is shown in Fig. 6a, and the failure process is depicted schematically in Fig. 6b. The adhesive bondline (a) was the weakest region as it damaged early in the fatigue process. The damage then propagated to the centre of the joint, with the propagation getting faster, particularly at the side where the butts existed. After propagating some distance from the overlap edge, the damage propagation increased rapidly until the failure of butt inside the stringer occurred (b). This then was followed by the failure of aluminium adjacent to the outside butt region (c) where a high stress concentration existed due to the failed butt. The final failure occurred at $\approx 89,800$ cycles.

\section{a. Hybrid FML doublers in tension}

Fig. 7 shows the load-life curves for all four joint configurations (see Fig. 2). It can be seen that the fatigue life for SP is highest followed by the $\mathrm{CH}$ without butt, $\mathrm{CH}$ with butt type-1 and the lowest is $\mathrm{CH}$ with butt type-2. This is consistent with the trend of static strengths. 
A summary of the key points of the fatigue failure process for all types of joints (see Fig. $8(a-d))$ is presented below. The stress concentration caused by the stringer acted to accelerate fatigue failure. The secondary bending in the specimen increased the stress level in the first aluminium layer close to the stringer edge and led to failure in this layer. It is also noticed that the site of subsequent failure may take a different route. For SP joints, the failure was under the stringer after the stringer bondline had been damaged. The high applied load in this joint caused significant damage of the stringer bondline, therefore the high stress concentration followed the remaining undamaged stringer bondline and the fatigue failure of the aluminium occurred well under the stringer. For $\mathrm{CH}$ without butt, the first fatigue failure occurred in the aluminium close to the stringer (outside the stringer). This was because the adhesive damage in the stringer bondline was not as large as for SP, as the applied load was lower than in SP. For CH-B1 and CH-B2, the first failure occurred in the aluminium adjacent to the butt. The fatigue failure of $\mathrm{CH}-\mathrm{B} 2$ was more severe, because the aluminium close to the stringer suffered from combined stress from the butt and also local bending.

\section{Numerical Modelling}

\subsection{Static modeling approach}

\section{a. Metal laminated doublers in tension}

When the doublers failed, it involved damage in the adhesive layer, butt and aluminium layer, therefore, progressive damage in all three were modelled. A cohesive zone model was used to model damage in the adhesive layer and butt. To model the failure of the aluminium layer, a continuum damage model was employed. Details of these failure

models can be found elsewhere [39]. The elastic properties of the materials are shown in Table 1, while the plasticity for the aluminium (longitudinal for ML) is shown in Table 2. 
Initiation in the continuum damage model requires the fracture strain $(0.0885)$, which is close to the equivalent plastic strain to failure of this aluminium (see Table 2) and stress triaxiality (0.33) [40]. The effective plastic displacement-based damage criterion was chosen for damage evolution. The plastic displacement at failure was taken as $0.01 \mathrm{~mm}$, which gives the total failure strain consistent with this aluminium.

To model the damage of adhesive layer in the bondlines and the butt a bi-linear tractionseparation law was employed. The quadratic nominal stress and an energy criterion were used to model damage initiation and damage evolution respectively. The quadratic nominal stress criterion considers the quadratic interaction between normal and shear tractions with damage initiating when the interaction reaches unity [39]. For damage evolution, mixed mode behaviour was employed by using a Benzeggagh and Kenane criterion [43] with the material parameter $\eta$ set as 2 . The properties of cohesive zone model are seen in Table 3 (as Cohesive-1) and they have been validated by the authors in previous modelling research $[13,15]$.

Fig. 9 shows the boundary condition and meshing used for the ML. The left end was fixed. The grip length was $40 \mathrm{~mm}$. Kinematic coupling was assigned on the right end to apply the displacement over the end face and obtain the total reaction force at the control node. The length of the cohesive element in the un-gripped region was $0.2 \mathrm{~mm}$, whereas in the gripped region it was $1 \mathrm{~mm}$ except where a butt was present (see the left grip). In the vicinity of the butt, the cohesive element mesh size was approximately $0.2 \mathrm{~mm} \times 0.2 \mathrm{~mm}$. The mesh size in the outer aluminium layer (most damaged) was $0.2 \mathrm{~mm} \times 0.2 \mathrm{~mm}$. The complete thickness of an adhesive layer was modelled using a single cohesive element, except the bondline between laminate and stringer. In this (main) bondline, because the 
thickness was not uniform, (being $0.1 \mathrm{~mm}$ at the overlap end and $0.2 \mathrm{~mm}$ at the overlap centre), the cohesive element was maintained at $0.1 \mathrm{~mm}$ thick with the remaining adhesive modelled using 4 node plane strain elements (CPE4). The butts were also modelled using strips of cohesive elements $0.2 \mathrm{~mm}$ thick at each end of the butt with the remaining adhesive modelled using the CPE4 elements. The fillet was not modelled because its contribution to the strength was not significant when the doubler is loaded in tension. The aluminium layer and the stringer were modelled using CPE4 elements. To obtain convergence of the model during damage progression, the viscosity coefficient was set at a small value of $10^{-5} \mathrm{Ns} / \mathrm{m}^{2}$ which gave a converged solution on the FE modeling [38].

\section{b. Hybrid FML doublers in tension}

The hybrid FML consisted of aluminium, adhesive and GFRP layers. To model the static failure of the hybrid FML joints, progressive damage of the GFRP layer and the GFRPaluminium and aluminium-aluminium bondlines were simulated. The latter 2 were modeled using cohesize zone models (as with the ML specimens). The damage in the GFRP was modeled using continuum damage for fibre reinforced composites. The detail of this modelling can be found elsewhere in [38]. For static loading the final aluminium sheet failure was not modelled but the aluminium plasticity was included in the model. The longitudinal and the transverse plasticity of the aluminium corresponded to the spanwise and chordwise directions respectively.

The properties of the aluminium and adhesive are shown in Table 1 and Table 2 respectively, while the properties of cohesive zone are as seen in Table 3. In Table 3, cohesive-1 represents the cohesive properties for the bonded stringer and butt where the bonding is good and cohesive-2 is for the weaker laminate bonding (see section 2.2 above). The traction and fracture energy for cohesive-2 were obtained by reducing cohesive-1 
properties by a factor 0.45 . This reduction factor was determined by correlating the numerical and experimental failure mechanisms and the ultimate load of chordwise with butt specimens. Table 4 presents the properties of the GFRP within the Glare (for spanwise and chordwise without butt), however when modeling chordwise with butt specimens, equivalent smeared material properties was used for the Glare (see Table 5 and 6).

FE modelling was carried out in 2D using ABAQUS 6.9.1. The models (Fig. 10) included the gripped region of the specimen. A fixed end boundary condition was applied on the left end of the FML joints. At the other end, kinematic coupling and displacement were applied. In the through-thickness direction the joint was restrained on the lower grip side only to allow for contraction (see Fig. 10a-b). The cohesive element size in the bondline and GFRP were approximately $0.2 \mathrm{~mm}$ x $0.5 \mathrm{~mm}$ and $0.01 \times 0.5 \mathrm{~mm}$ respectively (see Fig. 10). A 4-node bilinear plane strain quadrilateral element (CPE4) was used in the aluminium layers, in the stringer and in the smeared Glare (used with specimens with butts). The adhesive layers under the bonded stringer, in the laminate and in the resin rich GFRP-aluminium region were modelled using 4-node two dimensional cohesive elements. The GFRP was modelled using a 4-node bilinear plane stress quadrilateral element (CPS4). The larger butts were modelled with a combination of cohesive element strips and CPE4 elements as in the ML modeling.

As with ML, to obtain convergence of the model during damage progression, regularisation was used both in the cohesive zone and in the GFRP elements. For the cohesive zone, the viscosity coefficient was set at a small value of $10^{-5} \mathrm{Ns} / \mathrm{m}^{2}$, while for GFRP, the damage stabilisation was set as $0.00015 \mathrm{Ns} / \mathrm{m}^{2}$ for longitudinal and 0.0025 $\mathrm{Ns} / \mathrm{m}^{2}$ for transverse directions for both tension and compression respectively. Further 
details of these convergence procedures can be found elsewhere in ABAQUS

6.9.1documentation [39].

\subsection{Fatigue modelling approach}

\section{a. Metal laminated doublers in tension}

In the ML, most of load is carried by the aluminium laminate and the fatigue life was determined by the failure of aluminium rather than the adhesive bondline. Nevertheless, the all adhesive bondlines determined the integrity of the laminate and it also played an important role in the fatigue life and failure path. Thus, the fatigue damage of the aluminium and the adhesive bondline were simulated in predicting the fatigue life of ML specimens.

The fatigue damage was simulated by applying the maximum fatigue load statically in an incremental manner, each increment representing a block of cycles (Fig. 11). The properties of the adhesive cohesive zone and aluminium elements were degraded (using a cyclice fatigue damage law) with increasing cycles until the materials were no longer able to sustain the applied load and final failure occured. This is an approach that has been used successfully when modelling other bonded specimens and further details can be found elsewhere [41]. Fatigue degradation follows the strain-based fatigue damage law (see Eq. (1) and (2)). To model fatigue damage in aluminium, this model was applied to the parameters of the continuum damage model, while in the adhesive bondline and butt, the model (with different constants) was applied to the cohesive zone model parameters.

$$
\frac{\Delta D_{F}}{\Delta N}= \begin{cases}\alpha\left(\varepsilon_{\text {max }}-\varepsilon_{t h}\right)^{\beta}, & \varepsilon_{\text {max }}>\varepsilon_{t h} \\ 0, & \varepsilon_{\text {max }} \leq \varepsilon_{t h}\end{cases}
$$




$$
\varepsilon_{\text {max }}=\frac{\varepsilon_{n}}{2}+\sqrt{\left(\frac{\varepsilon_{n}}{2}\right)^{2}+\left(\frac{\varepsilon_{s}}{2}\right)^{2}}
$$

Where $\varepsilon_{\max }$ is maximum principal strain, $\varepsilon_{t h}$ is threshold strain below which no fatigue failure occurs, $\varepsilon_{n}$ and $\varepsilon_{s}$ are the normal strain and shear strain respectively and the parameters $\alpha$, and $\beta$ are material properties.

In the strain-based fatigue damage model, the parameter $\alpha, \varepsilon_{t h}$, and $\beta$ need to be calibrated against experimental data. The behavior of these parameters has been discussed elsewhere [41] and the calibrated parameters are summarised in Table 7.

\section{b. Hybrid FML doublers in tension}

The fatigue damage modelling approach in the aluminium, adhesive bondline and butts was the same as that used with the ML. The fatigue failure in GFRP was also modelled using a strain-based fatigue model. It should be noted that the fatigue failure of GFRP was not as important as the fatigue failure of the aluminium and adhesive as the fatigue life of the joints was mostly determined by the failure of the aluminium layer. The fatigue parameters are summarised in Table 7 . The different fatigue parameter for the cohesive zone model in ML and FML is due to the different properties of the adhesive, while for the aluminium, it is determined by the rolling direction (longitudinal for ML and FML spanwise, and transverse for FML chordwise).

\subsection{Static response}

\section{a. Metal laminated doubler in tension}

Fig. 12 shows the load-displacement of ML and plots of the equivalent stress and damage at the selected points. The experimental load-displacement response is also shown for 
comparison and further reference should be made to Fig. 4, where experimental video microscopy images of failure may be found. Good agreement was found between FEM and experimental results in terms of both failure load and failure mechanisms. The detail of predicted failure mechanism is presented below.

At point $1(35 \mathrm{kN})$, the butt inside the grip and the adhesive in the bondline between the laminate and stringer were damaged. Plastic deformation has occurred in the aluminium layer in the vicinity of the butt and also at the end of the overlap as the stress goes beyond the yield stress. With increased load, damage of the butt and the bondline increased until point $\mathbf{2}$, where the butt completely failed. Delamination of the aluminium layers also occurred due to the damage of adhesive around the failed butt. The aluminium plastic deformation in the vicinity of the failed butt increased and the maximum plastic deformation occured in the aluminium below the butt. At point $\mathbf{3}$, there was extensive delamination and the butt inside the overlap started to fail and the load capacity reduced, indicated by the dropping load after this point. With the increase of the damage of the butt and the associated delamination, the plastic deformation in the aluminium below the butt inside the grip continued to increase, as there is a redistribution of the load after butt inside the overlap failed. At point $4(35 \mathrm{kN})$, the aluminium below the butt inside the grip failed and the load continued to drop rapidly. The load then reached a plateau at approximately $25 \mathrm{kN}$. This corresponded to the strength of the remaining 3 aluminium layers). This plateau process is dominated by the delamination of the remaining aluminium layers. The predicted failure process was in good agreement with the experiment failure process (see Fig. 4). 


\section{b. Hybrid FML doublers in tension}

The detail predicted static strength and the failure mechanisms have been reported in detail elsewhere [38] and a summary of the predicted static response for all types of configuration is as seen in Fig. 4. The predicted failure load and failure mechanisms were in very good agreement with the experimental results.

\subsection{Fatigue response}

\section{a. Metal laminated doublers in tension}

Fig. 5 shows the predicted load-life curves and experimental data of ML. Very good agreement between predicted and experimental data was found. The detail predicted fatigue failure mechanism is presented below.

Fig. 13 shows the displacement (or compliance) during fatigue loading at a load level of $60 \%$ and plots of von Mises stress and fatigue damage at the selected points. Plastic deformation in the aluminium occurred at the end of the overlap during initial loading (point 1) to the maximum fatigue load. Some static damage (SDEG) also occurred in the adhesive bondline between stringer and laminate and also around the butts in the laminates. When the fatigue loading started, fatigue damage in the bondline between stringer and laminate occurred first and propagated towards the centre of the joints. The stress concentration in the aluminium also shifted towards the center of the joints. With increasing cycles modest fatigue damage in the aluminium initiated at the edge of overlap and spread away from the overlap in the outer layers of the aluminium (that experienced a combination of direct tension and tensile bending). As the outer butt can transfer only limited load and as delamination has occurred between adjacent aluminium layers, the load that was carried by the aluminium layers in-line with the butt was transferred to adjacent layer shifting the maximum von Mises stress into the aluminium layer above and below the 
outside butt. With increasing cycles, the fatigue damage in the aluminium continued to increase, particularly in the aluminium above and below the outside butt. At point 2 ( 88,000 cycles) fatigue damage in the bondline between the stringer and laminate started to propagate quickly and failure of butt within the overlap started to occur. This was the followed by yielding of the fatigue degraded aluminium layers close to the outer butt. As a result, the overall joint displacement started to increase rapidly. At point 3 ( 90,520 cycles), the inside butt completely failed. After this failure, redistribution of load occurred and the damage in the aluminium adjacent to the outside butt accelerated further. The aluminium under the outside butt completely failed first and this was followed by the aluminium above the same butt. The displacement increased very rapidly until complete failure of the joint occurred. Thus, from fatigue damage process described above, the butt (as well as aluminium layer) played an important role in determining the fatigue life of the ML joints. The butt acted as stress raiser which can serve as a site of fatigue failure for adjacent layers. The experimental evidence of this fatigue failure process shown in Fig. 6b, showing bondline damage, butt failure and then aluminium failure adjacent to the aouter butt, is entirely consistent with the predicted data.

\section{b. Hybrid FML doublers in tension}

Fig. 7 shows that the predicted load-life curves for SP, $\mathrm{CH}-\mathrm{NB}, \mathrm{CH}-\mathrm{B} 1$ and $\mathrm{CH}-\mathrm{B} 2$ were in good agreement with the experimental results. For all types of joints, the predicted fatigue life was determined when a layer of aluminium in the laminate failed and the displacement increased very rapidly with cycles. This seems to be consistent with the experimental data where the final failure of the joints occurred not long after a layer of aluminium in the laminate failed. More detail of fatigue failure process is given below. Only spanwise, chordwise without butt and chordwise with butt type-2 are discussed in this section, 
because the failure mechanism of the chordwise with butt type- 1 is similar to that in the ML.

\section{Spanwise: failure process}

Fig. 14 shows the predicted displacement response of the spanwise specimen with cycles at a load level of $60 \%$. Plots of von Mises stress and fatigue damage are shown at selected points on the curve. On initial loading to the maximum fatigue load (point 1), static damage was observed in the stringer bondline. Also the secondary bending induced by the stringer caused high stress in the aluminium laminate close to the edge of stringer exceeding the yield stress. As a result, localised plastic deformation occurred in this region which was thus more prone to fatigue failure. When the fatigue loading started, fatigue damage in the stringer bondline occurred. At 4,000 cycles considerable fatigue damage in that bondline was observed. This then propagated to the centre of the joint with increasing cycles. Modest fatigue damage in the aluminium occurred that increased (value and extent) steadily with increasing cycles. At around 23,800 cycles (point 2), the fatigue damage in the aluminium close to the edge of stringer was significant and failure initiated in that region. After this point, the displacement increased very rapidly. The top layer of aluminium failed and this was followed by damage (debonding) in the adhesive layer in the laminate. The Glare, which possessed excellent fatigue performance due to its high strength, resisted the fatigue damage and deflected the aluminium crack propagation through the adhesive layer (point 3). This predicted failure mechanism is in good agreement with the experimental result (see Fig. 8a) which shows bondline failure, followed by aluminium cracking and crack deflection by the Glare. 


\section{Chordwise without butt: failure process}

Fig. 15 shows the variation of the predicted displacement (specimen compliance) with cycles for the chordwise without butt specimen during the fatigue loading at a load level of $60 \%$. The fatigue damage progress has been illustrated at a selected number of cycles. Again, the initial loading to the maximum load induced secondary bending and created high stress in the aluminium close to the edge of stringer (point 1). Plastic deformation was observed in this region, however, the value and the extent was much smaller than that in the spanwise specimen as the maximum load applied was smaller. Static damage in the stringer bondline was also observed. As the fatigue loading started, fatigue damage in the stringer bondline occurred, as with the spanwise specimen, and then continued to propagate to the centre of the joint. Aluminium fatigue damage also developed from a modest value in the early cycles to being significant at 3,000 cycles. Global fatigue damage started from those cycles, as the displacement began to increase very rapidly. At point $\mathbf{2}$, the first aluminium layer failed and the rate of damaged further increased. The final failure path is different to the spanwise specimen, where the crack was deflected to propagate in the adhesive layer. In the chordwise specimen, the crack propagated further into the Glare and aluminium layer underneath. This was a result of weak fatigue resistance of Glare when the fibre was running perpendicular to the loading direction. The crack continued to propagate across the laminate until final failure occurred (point $\mathbf{3}$ ) and this is in agreement with the experimental failure mechanism (see Fig. 8b), which shows bondline damage followed by aluminium cracking and finally Glare cracking.

\section{Chordwise with butt type-2: failure process}

Fig. 16 shows the predicted displacement and plots of von Mises stress and damage at the selected cycles in the chordwise with butt type- 2 specimen at a load level $60 \%$ of its static strength. Again, the secondary bending due to static loading to the maximum load 
increased the stress in the laminate around the edge of stringer (point 1). Even with the lowest load applied (25\% less than chordwise without butt specimen) the stress value was higher than that in the chordwise without butt, because the butts in this joint are located in the critical area, are damaged and raise the local aluminium stresses.

As soon as the fatigue loading began, fatigue damage in the stringer bondline and the butts occurred (at 4,000 cycles). The stress in the aluminium close to the edge of stringer decreased as the high stress region followed the bondline damage under the overlap. Very small fatigue damage in the aluminium layer also occurred. The fatigue damage in the bondline, butts and aluminium continued to increase in a steady manner until the fatigue damage in the aluminium close to the edge of stringer was significant, causing aluminium failure at point $\mathbf{2}$, and the displacement began to increase very rapidly. The load then transferred into the remaining, less damaged, aluminium layers. At point $\mathbf{3}$, fatigue failure

occurred in the aluminium adjacent to the small butt (bottom layer) leading to final failure of the joint. This corresponds to the experimental evidence, see Fig. 8d, which shows bondline and butt failure, followed by aluminium failure running through the laminate

\section{Conclusions}

Experimental and numerical studies on metal laminate and hybrid FML doublers loaded in tension have been successfully undertaken. The effect of butts in the laminate was investigated. In ML, for the static response, the butts in the laminate seem to be a potential site of the failure initiation, because the final failure of the joints often initiated from the failure of the butt. In hybrid FML (both spanwise and chordwise specimens without butts), Glare fibre failure controlled the ultimate static strength of the joints, whereas for chordwise specimens with butts, the butts controlled the ultimate static strength. 
In ML, again the butts are a potential site of the fatigue failure, because the fatigue failure of the aluminium occurred near to the failed butt. In hybrid FML, for spanwise and chordwise specimens without butts, the fatigue failure initiated in the aluminium layer close to the stringer edge due to the high stress in this region which caused localised plastic deformation. Thus, the aluminium failure controlled the fatigue strength of the joints. Further, specimens with Glare where the fibre ran along the loading direction have better fatigue performance than the aluminium in the main laminate of FML and it deflected the crack to propagate through the adhesive bondline before the complete failure, whereas the specimens with the fibre running perpendicular to the loading direction were more susceptible to the fatigue failure through the laminate. For chordwise specimens with butts, as with the static response, the butts played an important role in the fatigue failure.

A cohesive zone model (with properties having been calibrated in other joints i.e single lap joints and laminated doublers in bending [15]) was successfully used to model the adhesive layer and butt damage. A continuum damage model was also successfully used to model the damage of the aluminium layers and the fibres. For both ML and hybrid FML, the predicted static strength and the damage mechanism were found in a good agreement with the experimental data. A relatively simple strain-based fatigue damage model was used to successfully degrade the continuum damage and the cohesive zone models in the ML and the hybrid FML doublers subjected to cyclic tensile loads. The predicted fatigue strength and failure mechanisms were in good agreement with those observed experimentally for both ML and hybrid FML.

Inevitably butts that exist in the ML and hybrid FML doublers joints loaded in tension decrease their static and fatigue performance, particularly where butts position is close to 
the stringer edge. Thus it is recommended that the butts be placed away from the stringer edge. urther, although Glare with the fibres aligned in the loading direction increase the static and fatigue performance of the hybrif FML doublers, the fatigue failure is still initiated in the aluminium layer close to the stringer edge where high stress exists due to secondary bending and load transfer. Therefore, the design of laminate structures with the doublers loaded in tension should, where possible, minimise the high stress in the aluminium layer close to the stringer edge by using techniques such as stringer run out (tapering). In any event, the methodology and procedures outlined in this paper can be used to establish safe working loads..

\section{Acknowledgements}

The authors would like to thank Airbus (Bristol, UK) who supplied the metal laminate and the hybrid FML and stringer material. Also thanks to Directorate General of Higher Education, Ministry of Education, Republic of Indonesia which support funding in this research.

\section{References}

[1] Vlot A. Glare. History of the development of a new aircraft material. Dordrecht: Kluwer Academic Publishers, 2002.

[2] Schijve J, Van Lipzid HTM, Van Gestel GFJA, and Hoeymakers AHW. Fatigue properties of adhesively-bonded laminated sheet materials of aluminium alloys. Engineering Fracture Mechanic 1979; 12: 561-579.

[3] Vlot AD. Historical overview. In: Vlot AD, Gunnink JW, editors. Fiber Metal Laminates. An Introduction. Dordrecht: Kluwer Academic Publishers, 2001. p. 3-21. 
[4] Kawai M, Hachinohe A, Takumida K, Kawase Y. Off-axis fatigue behavior and its damage mechanics modeling for unidirectional fibre-metal hybrid composite: GLARE 2. Composites Part A: Applied Science and Manufacturing 2001; 32(1): 13-23.

[5] Marissen R. Fatigue crack growth in arall, a hybrid aluminium-aramid composite material, crack growth mechanism and quantitative predictions of the crack growth rate. PhD thesis. TU Deflt, Delft, 1988.

[6] Alderliesten RC. Fatigue, In: Vlot, AD, Gunnink JW, editors. Fiber Metal Laminates. An Introduction. Dordrecht: Kluwer Academic Publishers, 2001. p. 3-21.

[7] Vogelesang LB, and Vlot A. Development of fiber metal laminates for advanced aerospace structures. Journal of Material Processing and Technology 2000; 103: 1-5.

[8] Alderliesten RC, Homan JJ. Fatigue and damage tolerance issues of Glare in aircraft structures. International Journal of Fatigue 2006; 28: 1116-1123.

[9] Asundi A, and Choi AYN. Fiber metal laminates: An advanced material for future aircraft. Journal of Material Processing and Technology 1997; 63: 384-394.

[10] de Vries TJ, Vlot A, Hashagen F. Delamination behavior of spliced Fiber Metal Laminates. Part. 1 Experimental result. Composite Structures 1999; 46: 131-145.

[11] Van der Jagt OC, and Out BCL. Detailed design concepts. In: Vlot AD, Gunnink JW, editors. Fiber Metal Laminates. An Introduction. Dordrecht: Kluwer Academic Publishers, 2001. p. 267-280.

[12] Liljedahl CDM, Crocombe AD, Wahab MA, Ashcroft IA. Damage modelling of adhesively bonded joints. International Journal of Fracture 2006; 141(1): 147-161.

[13] Katnam K, Sargent JP, Crocombe AD, Khoramishad H, Ashcroft IA. Characterisation of moisture-dependent cohesive zone properties for adhesively bonded joints. Engineering Fracture Mechanic 2010; 77: 3105-3119. 
[14] Katnam KB, Crocombe AD, Khoramishad H, Ashcroft IA. The Static failure of adhesively bonded metal laminate structures: A cohesive zone approach. Journal of Adhesion Science and Technology 2009; 25: 1131-1157.

[15] Sugiman S, Crocombe AD, Aschroft IA. Experimental and numerical studies on the static and fatigue response of environmentally degraded adhesively bonded aluminium joints. Adhesion '11. The $11^{\text {th }}$ Triennial International Conference on the Science and Technology of Adhesion and Adhesives, York, UK, 7-9 September 2011. p. 71-74.

[16] Bianchi S, Corigliano A, Frassine R, Rink M. Modelling of interlaminar fracture processes in composites using interface elements. Composites Science and Technology 2006; 66: 255-263.

[17] Alfano G, And Crisfield MA. Finite element interface models for the delamination analysis of laminated composites: Mechanical and computational issues. International Journal for Numerical Methods in Engineering 2001; 50: 1701-1736.

[18] Turon A, Camanho PP, Costa J, Davila CG. A damage model for the simulation of delamination in advanced composites under variable-mode loading. Mechanics of Materials 2006; 38: 1072-1089.

[19] Geubelle PH, and Baylor JS. Impact-induced delamination of composites: A 2D simulation. Composites: Part B 1998; 29B: 589-602.

[20] Khoramishad H, Crocombe AD, Katnam KB, Aschroft IA. Predicting fatigue damage in adhesively bonded joints using a cohesive zone model. International Journal of Fatigue 32(7) (2010) 1146-1158.

[21] Khoramishad H, Crocombe AD, Katnam KB, Aschroft IA. A generalised damage model for constant amplitude fatigue loading of adhesively bonded joints. Int. J. Adhesion and Adhesives 30 (2010) 513-521. 
[22] Iannucci L, and Willows ML. An energy based damage mechanics approach to modelling impact onto woven composite materials-Part I: Numerical models. Composites: Part A 2006; 37: 2041-2056.

[23] Donadon MV, Iannucci L, Hodgkinson JM, de Almeida SFM. A progressive failure model for composite laminates subjected to low impact damage. Computers and Structures 2008; 86: 1232-1252.

[24] Lapczyk I, and Hurtado JA. Progressive damage modelling in fiber reinforced materials. Composites: Part A 2007; 38: 2333-2341.

[25] Wu F, and Yao W. A fatigue damage model of composite materials. International Journal of Fatigue 2010; 32: 134-138.

[26] Mao H, and Mahadevan S. Fatigue damage modelling of composite materials. Composite Structures 2002; 58: 405-410.

[27] Coffin LF. Fatigue in machines and structures-power generation. In: Fatigue and Microstructure (ASM), 1978. p. 4-7.

[28] Manson SS. Fatigue: A complex subject-some simple approximations. Experimental Mechanic 1965; 15(7): 193-226.

[29] Dowling NE. Notched member fatigue life predictions combining crack initiation and propagation. Fatigue of Eengineering Materials and Structures 1979; 2: 129-138.

[30] Przekop A, Rizzi SA, Sweitzer KA. An investigation og high-cycle fatigue models for metallic structures exhibiting snap-through response. $48^{\text {th }}$ AIAA/ASME/ASCE/AHS/ASC Structures. Structural Dynamics, and Materials Conference, Honolulu, Hawai, 23-26 April 2007. p. 1-18.

[31] Che HY, Zhu L, Sun DZ, Chen JH, Zhu H. Characterization and modelling of aluminium extrusion damage under crash loading. Thin-Walled Structures 2007; 45: 383-392. 
[32] Hambli R. Comparison between Lemaitre and Gurson damage models in crack growth simulation during blanking process. International Journal of Mechanical Sciences 2001; 43: 2769-2790.

[33] Hambli R, and Badie-Levet D. Damage and fracture simulation during the extrusion processes. Computer Methods Appl. Mech. Engineering 2000; 186: 109-120.

[34] Bonora N. A nonlinear CDM model for ductile failure. Engineering Fracture Mechanics 1997; 58(1/2): 11-28.

[35] Bonora N, Gentile D, Pirondi A, Newaz G. Ductile damage evolution under triaxial state of stress: theory and experiments. International Journal of Plasticity 2005; 21: 981-1007.

[36] Woerden HJM, Mortier WJ, Guijt CB, Verhoven S. Bonded repair patches. In: Vlot AD, Gunnink JW, editors. Fiber Metal Laminates. An Introduction. Dordrecht: Kluwer Academic Publishers, 2001. p. 451-475.

[37] Cytec Engineered Materials. FM® 73 Toughened Epoxy Film. Maryland, 1998.

[38] Sugiman S, Crocombe AD, Katnam KB. Investigating the static response of hybrid fibre-metal laminate doublers loaded in tension. Composite Part B: Engineering 2011; 42(7): 1867-1884.

[39] ABAQUS. User Manual, version 6.9.1. Habbit, Karlsson \& Sorensen, Inc., USA, 2009.

[40] Hooputra H, Gese H, Dell H, and Werner H. A comprehensive failure model for crashworthiness simulation of aluminium extrusions. International Journal of Crashworthiness 2004; 9(5): 449-464.

[41] Khoramishad H. Modelling fatigue damage in adhesively bonded joints. PhD Thesis. University of Surrey, Guildford, UK, 2010. 
[42] Liljedahl CDM, Crocombe AD, Wahab MMA, Aschroft IA. Modelling the environmental degradation of the interface in adhesively bonded joints using cohesive zone approach. The Journal of Adhesion 2006; 82: 1061-1089.

[43] Benzeggagh ML, and Kenane M. Measurement of mixed-mode delamination fracture toughness of unidirectional glass/epoxy composites with mixed-mode bending apparatus. Composites Science and Technology 1996; 56:439-449.

[44] Airbus report. Airbus Material Specification: Unidirectional glass fibre reinforced epoxy prepreg for application in Fibre Metal Laminates (FML). Ref. no. AIMS05-13001, 2007.

[45] Airbus report. Airbus Material Specification: Fibre metal laminates of glass fibre reinforced aluminium for application at $-55^{\circ} \mathrm{C}$ to $80^{\circ} \mathrm{C}$. Type 2. Ref. no. AIMS 03-14$001,2005$.

[46] Hagenbeek M, Van Hengel C, Bosker OJ, and Vermeeren CAJR. Static properties of fibre metal laminates. Applied Composite Materials 2003; 10: 207-222. 


\section{List of Figures}

Fig. 1 The ML specimen.

Fig. 2 The hybrid FML specimens, (a) CH-B1, (b) CH-B2. The dimension of SP and CHNB specimen are the same (but without butts).

Fig. 3 (a) Load-displacement of ML, (b) The damage process of ML in static tension.

Fig. 4 Load-displacement response of hybrid FML doublers in tension.

Fig. 5 Load-life curve of metal laminate doublers in tension.

Fig. 6 (a) Photograph of failed ML under fatigue loading, (b) Schematic representation of the fatigue failure process of the same joint.

Fig. 7 The fatigue life of hybrid FML joints.

Fig. 8 The fatigue failure process of hybrid FML under tension loading, (a) SP, (b) $\mathrm{CH}$ $\mathrm{NB}$, (c) $\mathrm{CH}-\mathrm{B} 1$, (d) $\mathrm{CH}-\mathrm{B} 2$.

Fig. 9 Boundary condition and meshing of LDT.

Fig. 10 The boundary condition and mesh for (a) spanwise and chordwise joints (no butts) and (b) chordwise with butt joints.

Fig. 11 Modelling approach of fatigue loading.

Fig. 12 Experimental and predicted load-displacement curves of FEM and plots of equivalent stress and damage at the selected points.

Fig. 13 (a) Plot of displacement of ML under fatigue loading at load level 60\%. (b) Plots of von Mises stresses and fatigue damage are shown at the selected points.

Fig. 14 The contour plots at the selected points of fatigue failure process of SP at load level of $60 \%$.

Fig. 15 The contour plots at the selected points of fatigue failure process of $\mathrm{CH}-\mathrm{NB}$ at load level of $60 \%$.

Fig. 16 The contour plots at the selected points of fatigue failure process of $\mathrm{CH}-\mathrm{B} 2$ at load level of $60 \%$. 


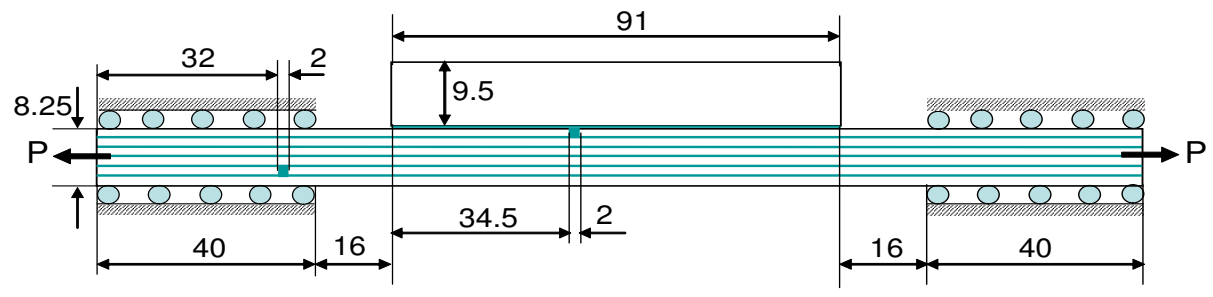

Specimen width: $15 \mathrm{~mm}$ Unit: $\mathrm{mm}$

Fig. 1 The ML specimen.

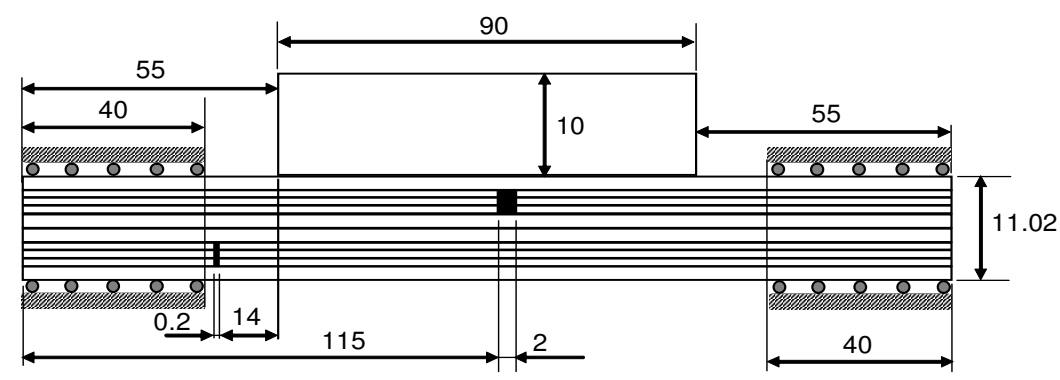

(a)

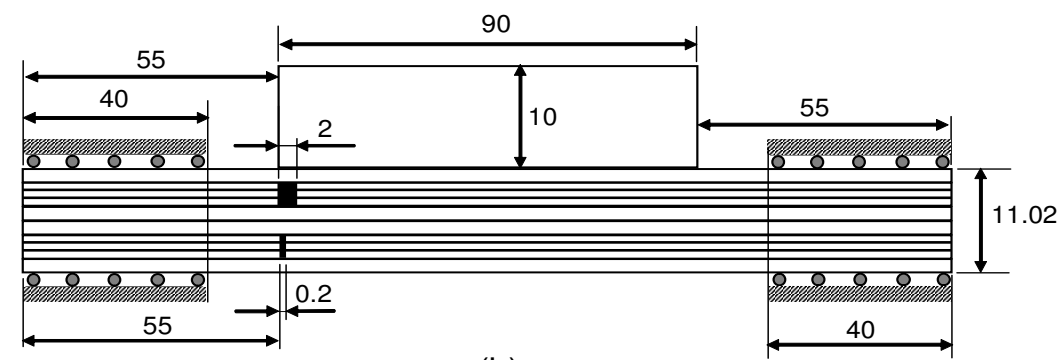

(b)

Specimen width $=15 \mathrm{~mm}$

Unit $=\mathrm{mm}$

Fig. 2 The hybrid FML specimens, (a) $\mathrm{CH}-\mathrm{B} 1$, (b) $\mathrm{CH}-\mathrm{B} 2$. The dimension of SP and $\mathrm{CH}-$ NB specimen are the same (but without butts). 


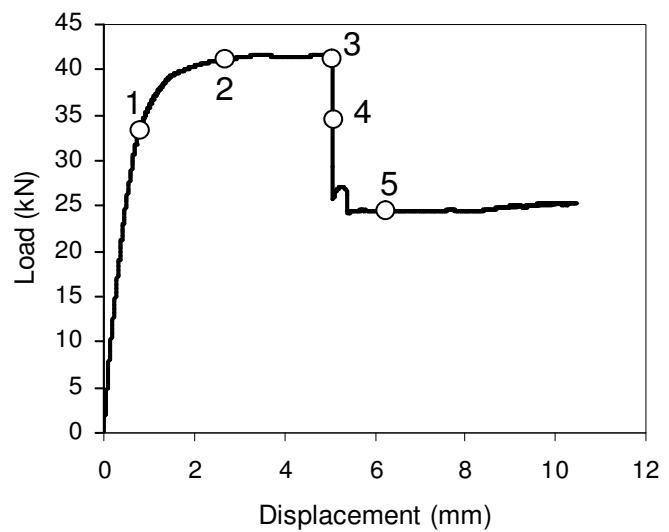

(a)

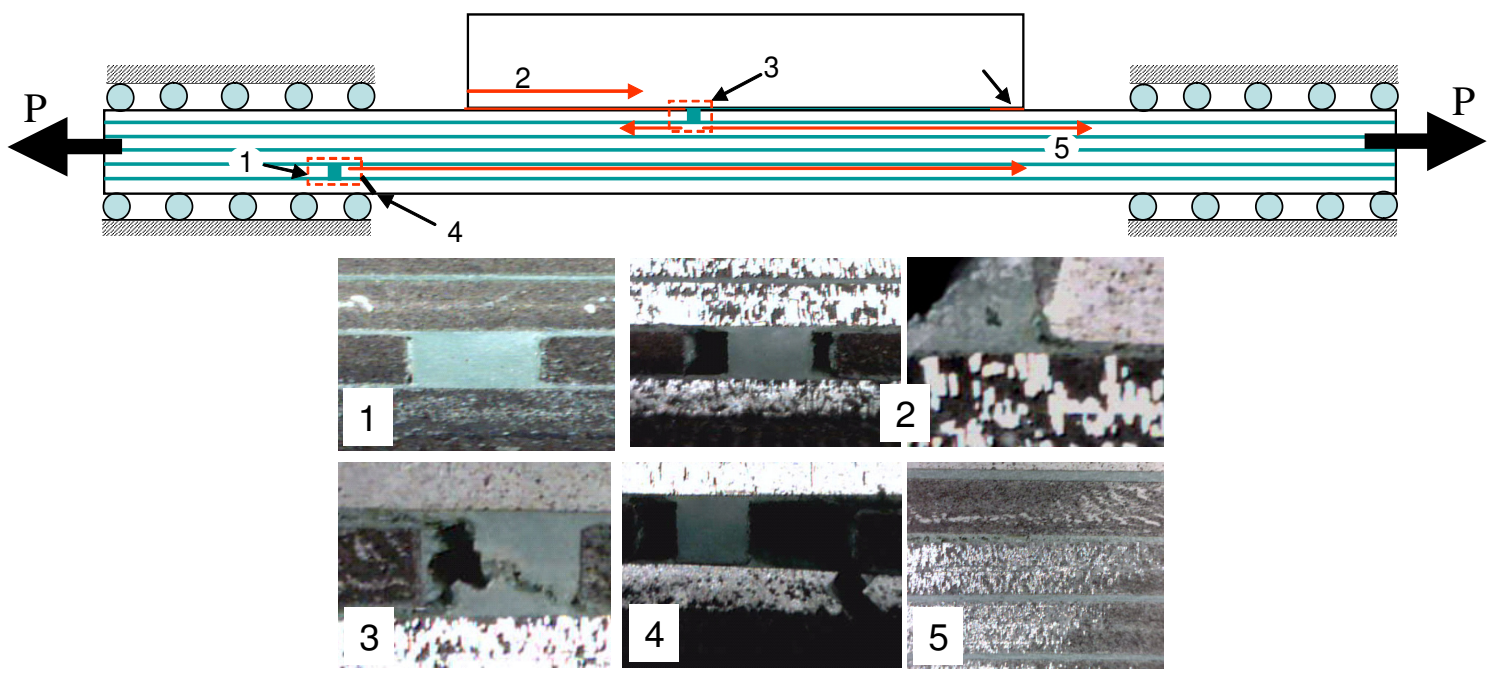

(b)

Fig. 3 (a) Load-displacement of ML, (b) The damage process of ML in static tension.

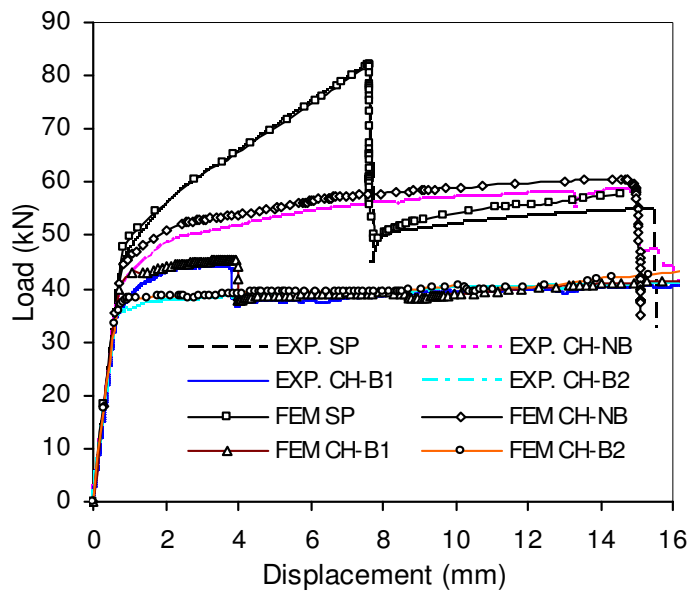

Fig. 4 Load-displacement response of hybrid FML doublers in tension. 


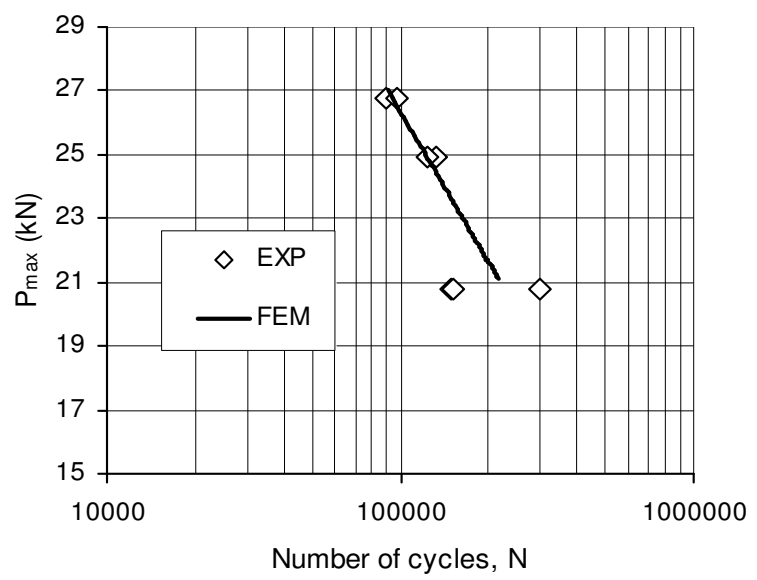

Fig. 5 Load-life curve of metal laminate doublers in tension.

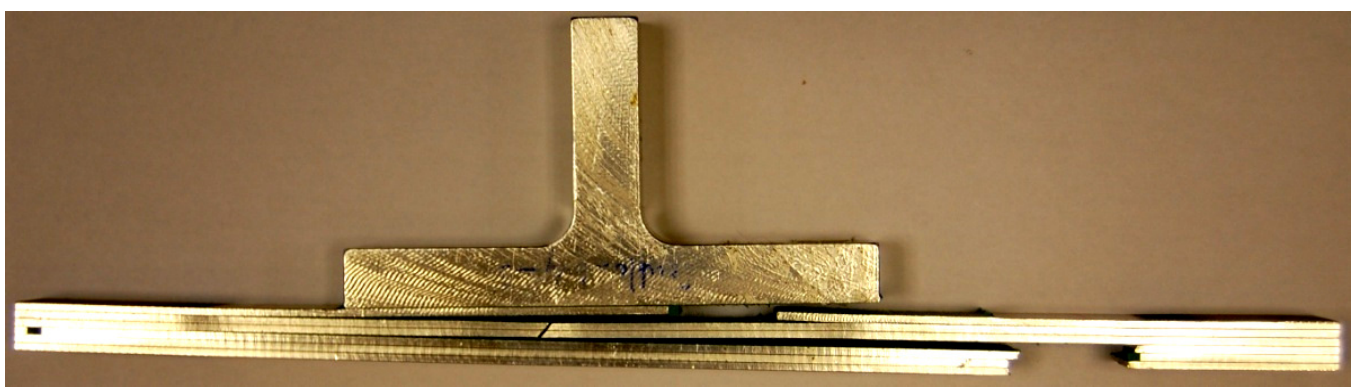

(a)

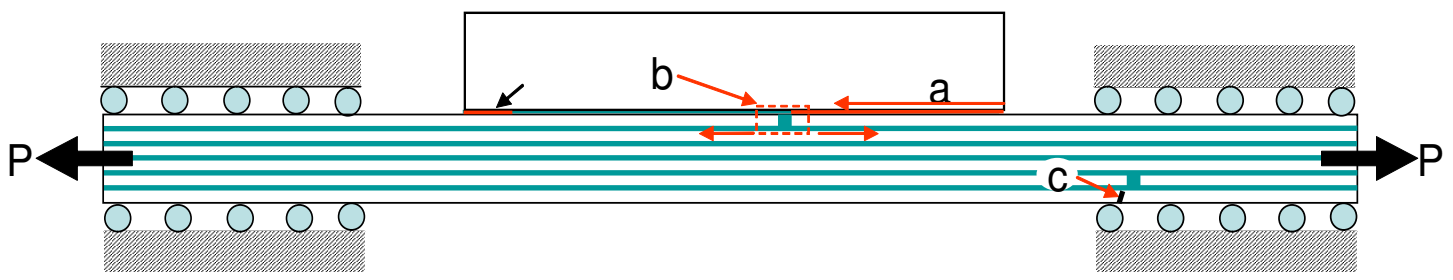

(b)

Fig. 6 (a) Photograph of failed ML under fatigue loading, (b) Schematic representation of the fatigue failure process of the same joint. 


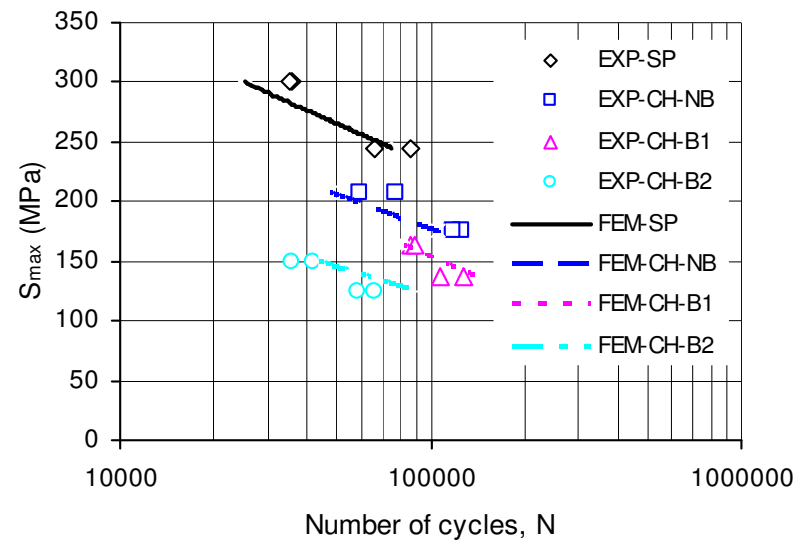

Fig. 7 The fatigue life of hybrid FML joints.

(a)
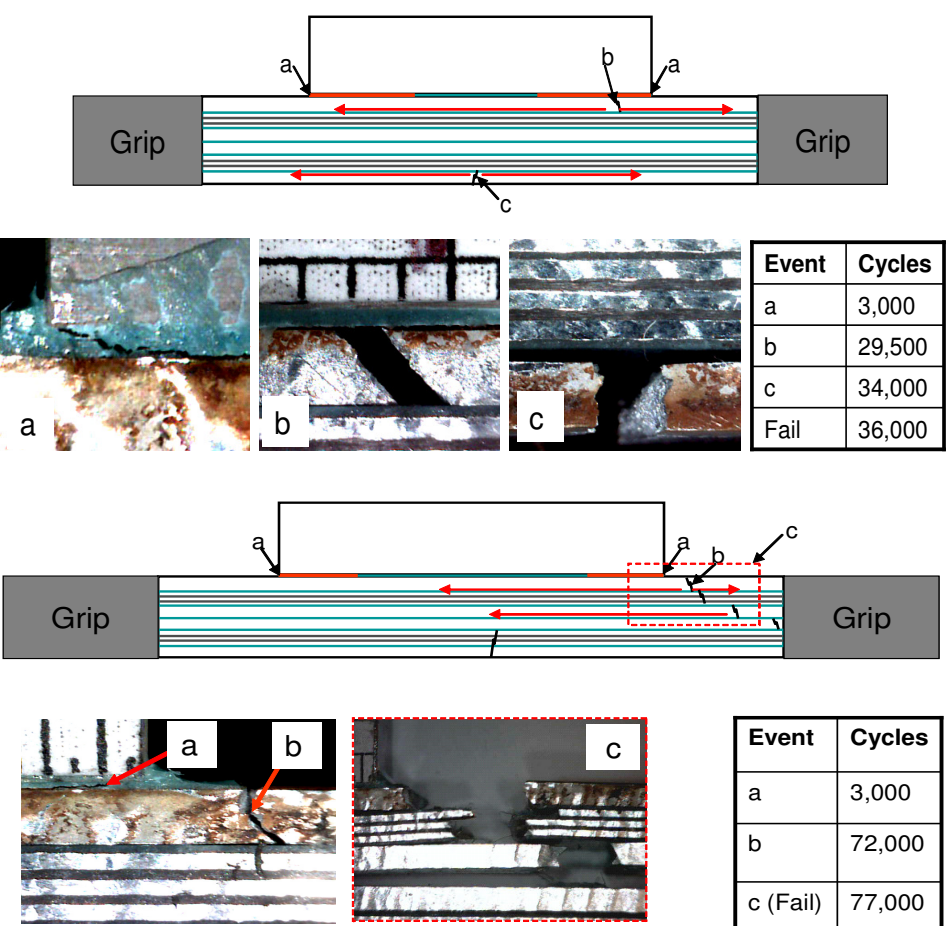

\begin{tabular}{|l|l|}
\hline Event & Cycles \\
\hline a & 3,000 \\
\hline b & 72,000 \\
\hline c (Fail) & 77,000 \\
\hline
\end{tabular}


(c)
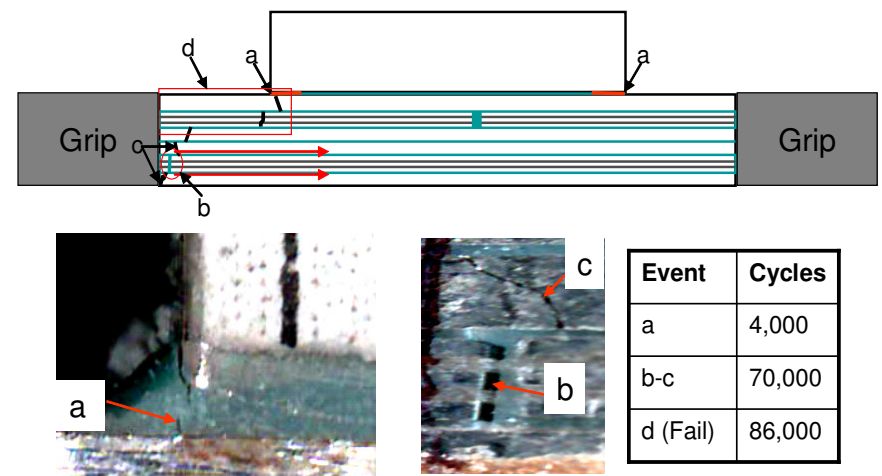

(d)
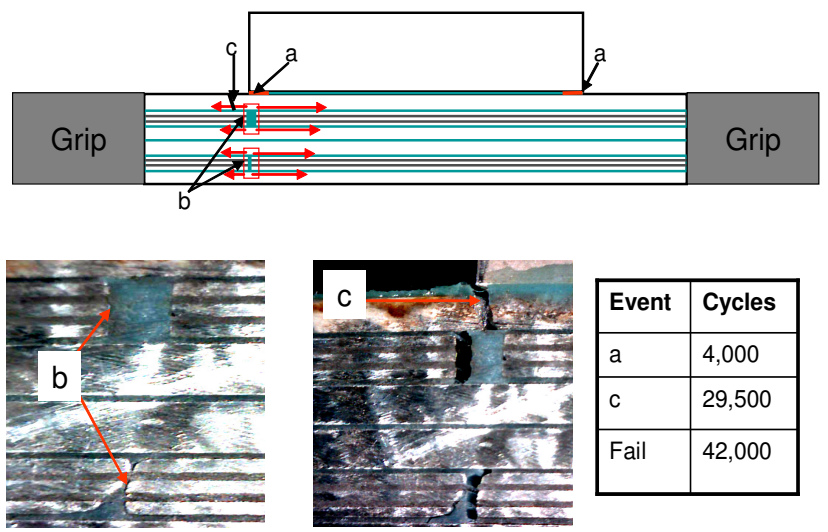

\begin{tabular}{|l|l|}
\hline Event & Cycles \\
\hline a & 4,000 \\
\hline C & 29,500 \\
\hline Fail & 42,000 \\
\hline
\end{tabular}

Fig. 8 The fatigue failure process of hybrid FML under tension loading, (a) SP, (b) CH$\mathrm{NB},(\mathrm{c}) \mathrm{CH}-\mathrm{B} 1$, (d) $\mathrm{CH}-\mathrm{B} 2$.

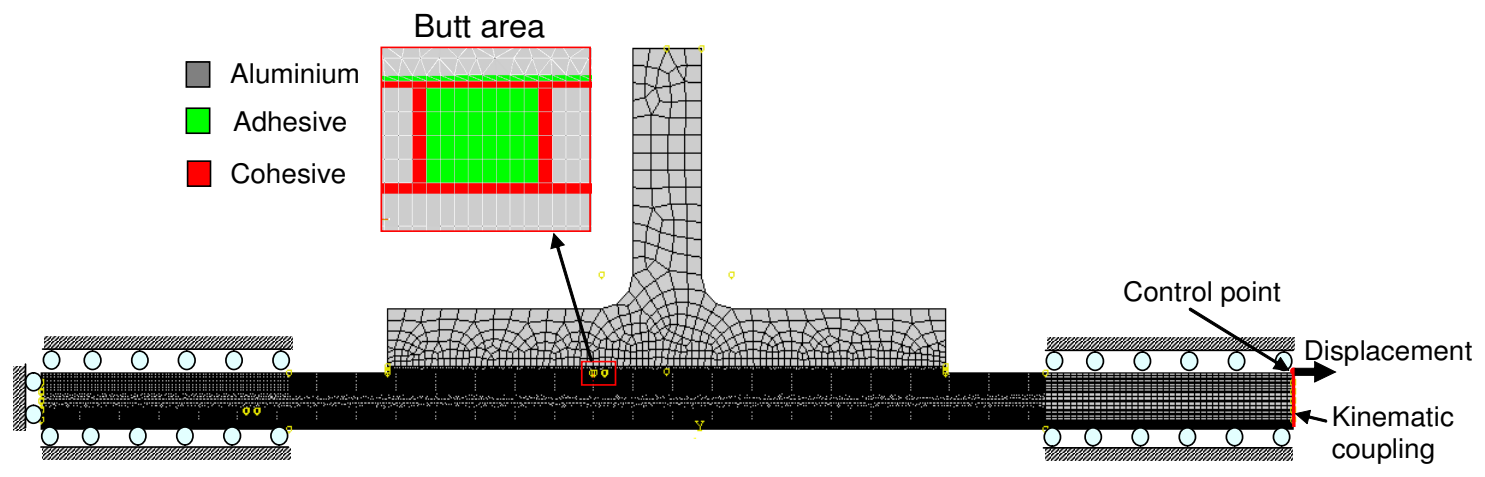

Fig. 9 Boundary condition and meshing of LDT. 


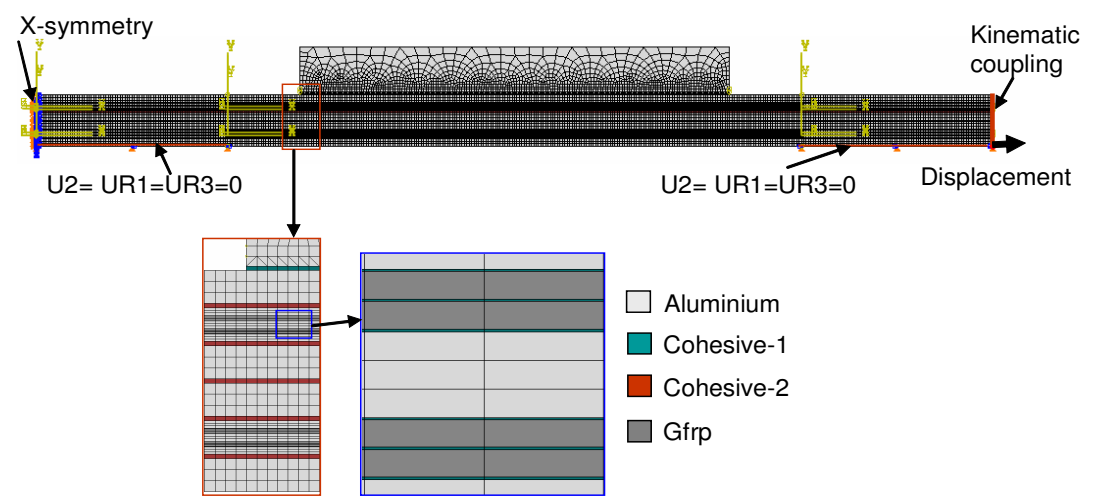

(a)

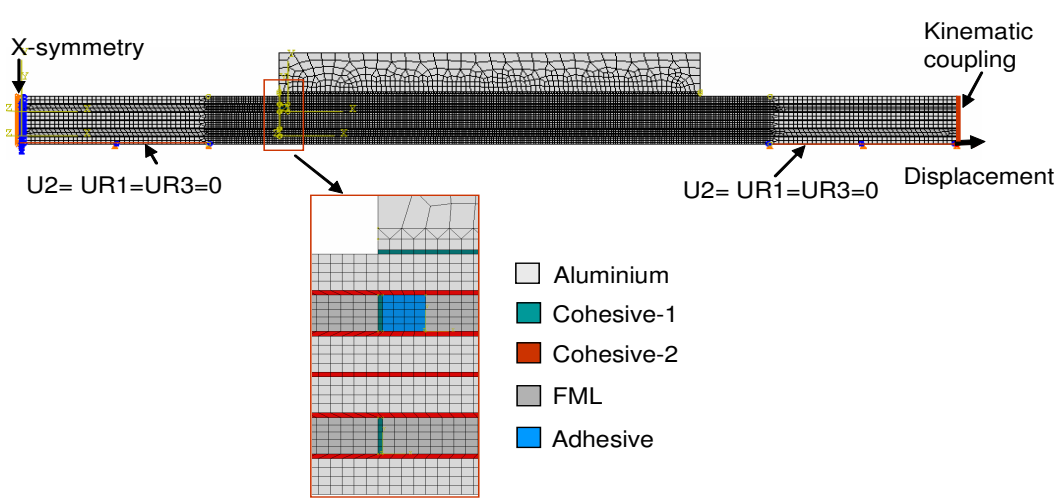

(b)

Fig. 10 The boundary condition and mesh for (a) spanwise and chordwise joints (no butts) and (b) chordwise with butt joints.

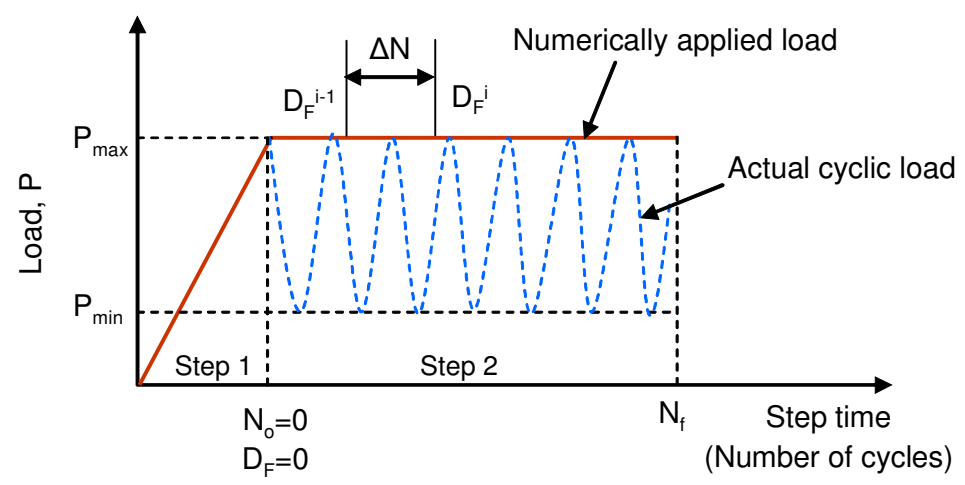

Fig. 11 Modelling approach of fatigue loading. 

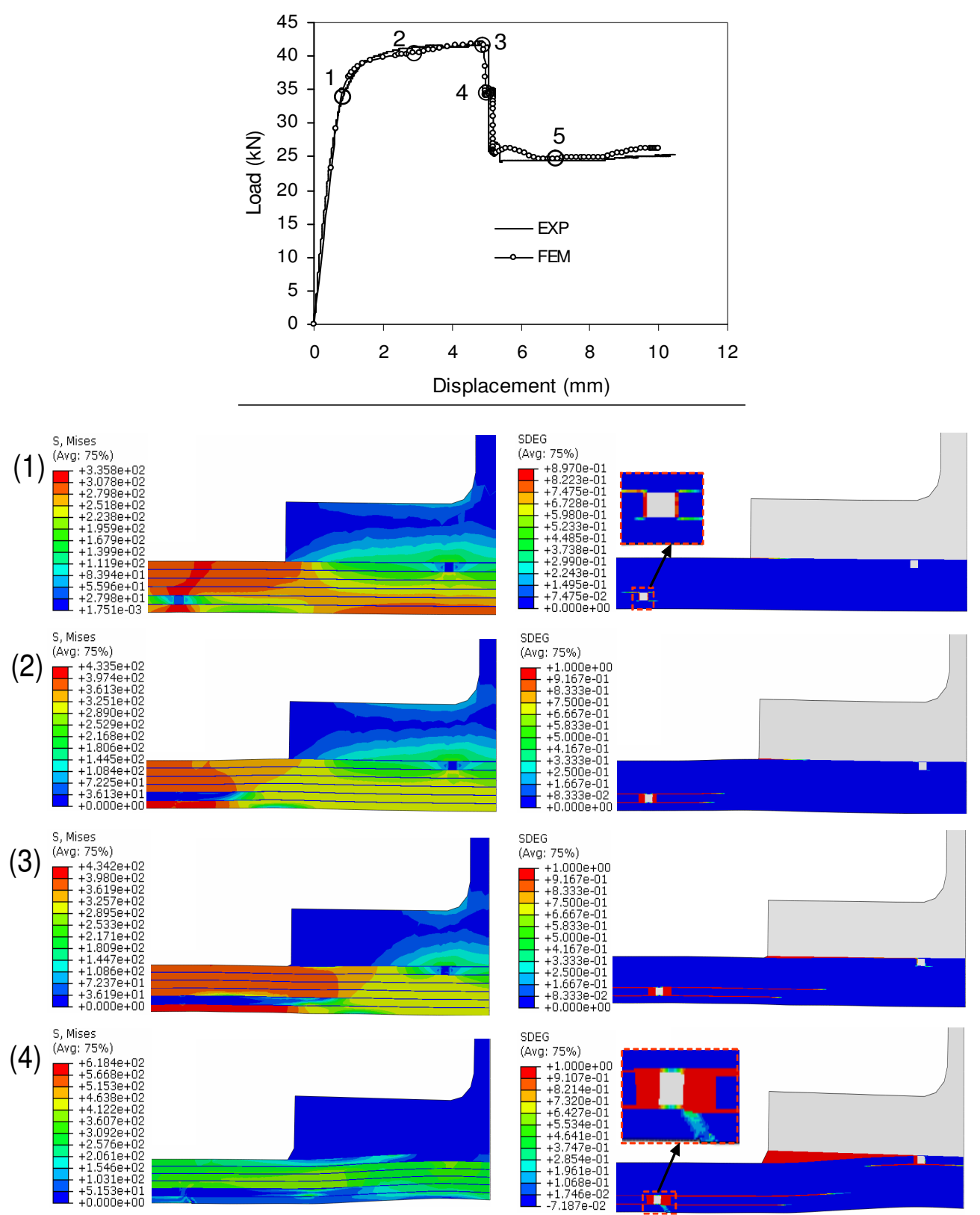

Fig. 12 Experimental and predicted load-displacement curves of FEM and plots of equivalent stress and damage at the selected points.

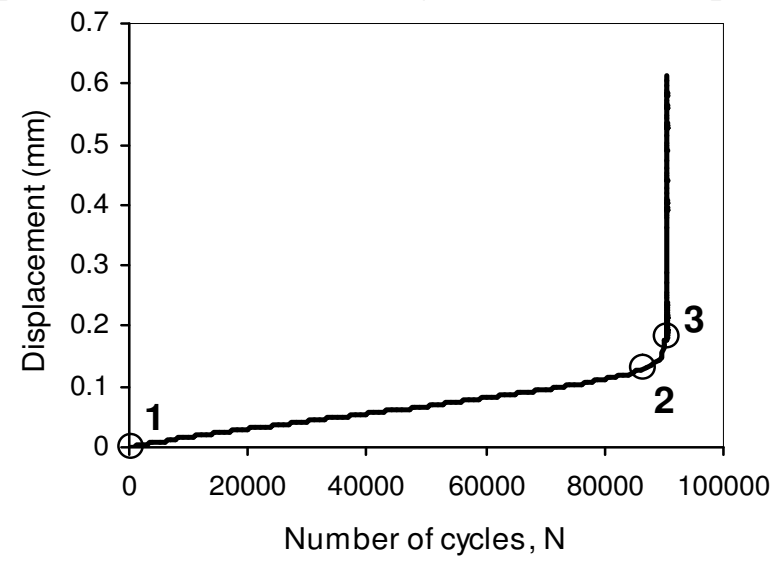

(a) 


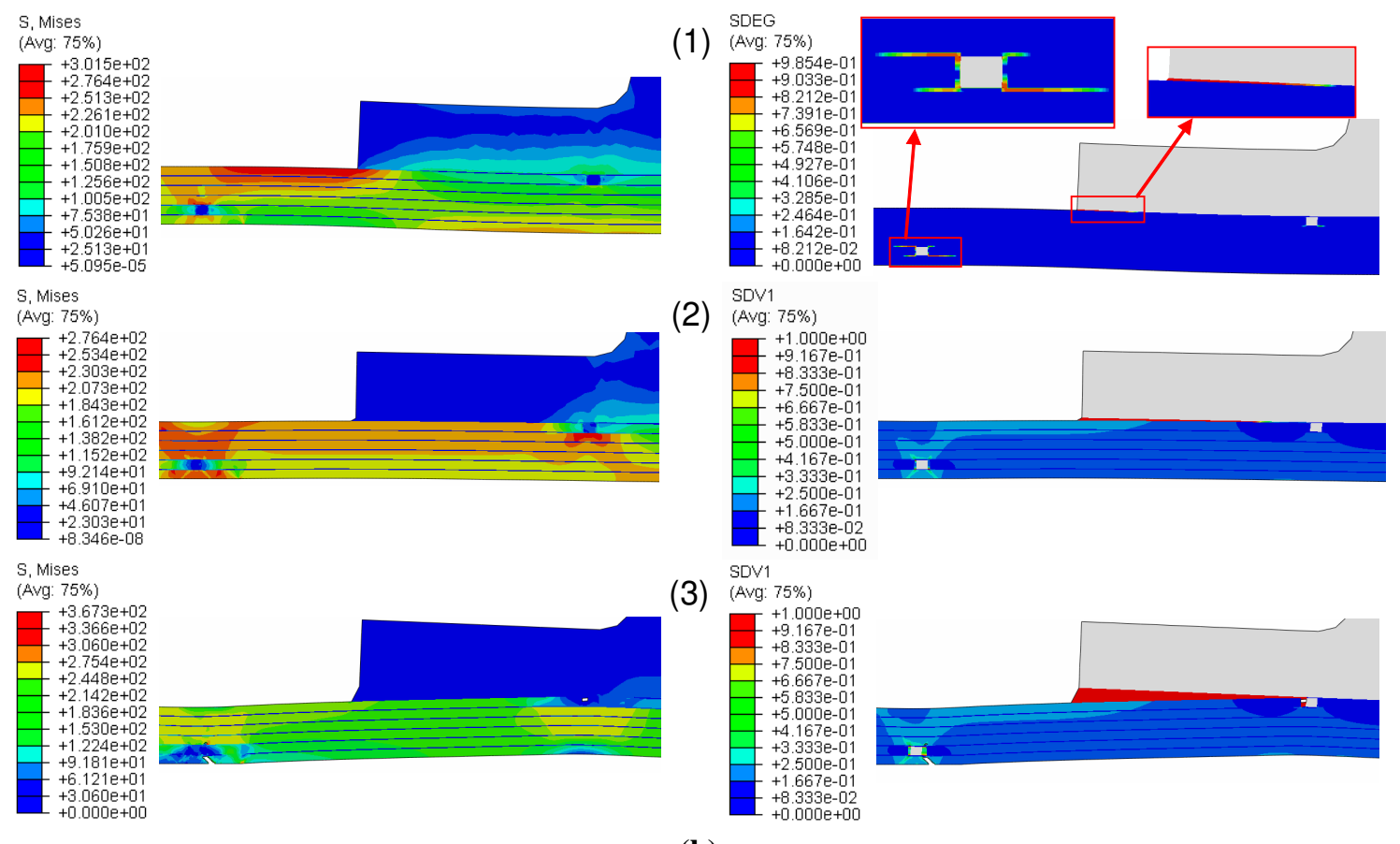

(b)

Fig. 13 (a) Plot of displacement of ML under fatigue loading at load level 60\%. (b) Plots of von Mises stresses and fatigue damage are shown at the selected points. 

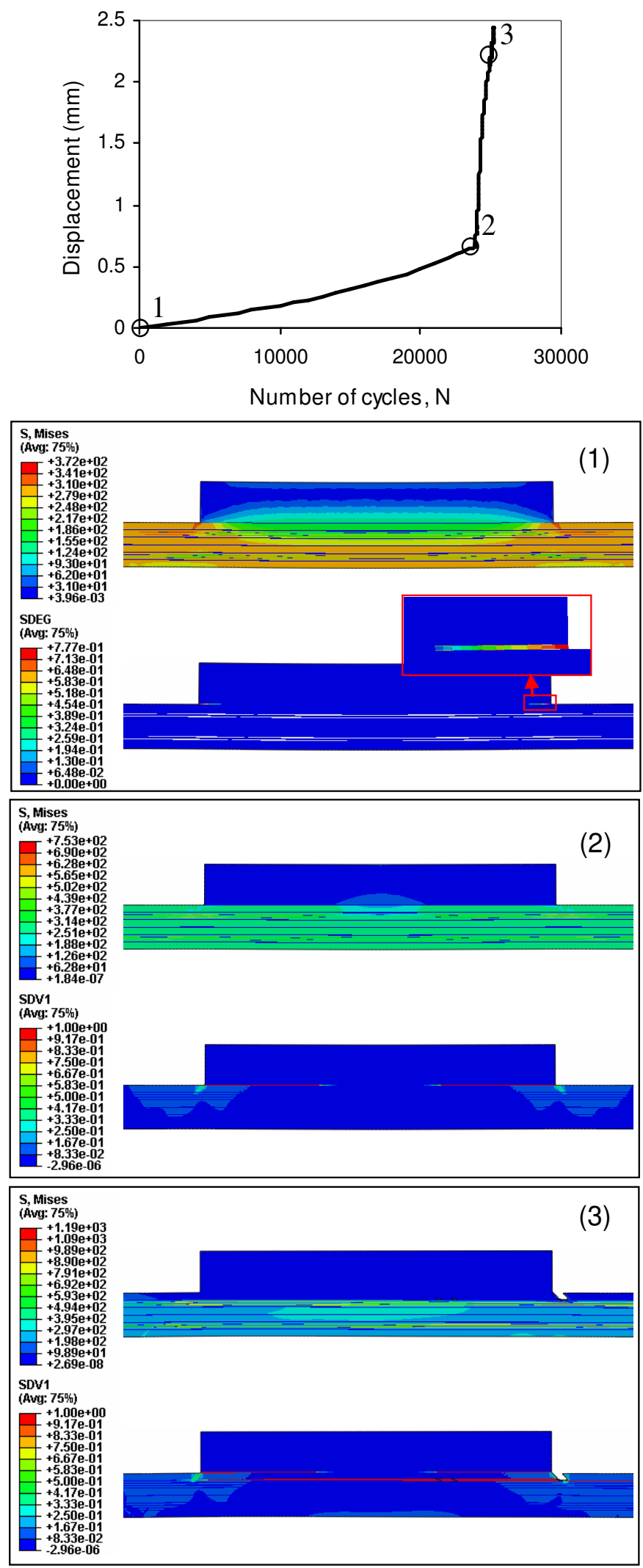

Fig. 14 The contour plots at the selected points of fatigue failure process of SP at load level of $60 \%$. 

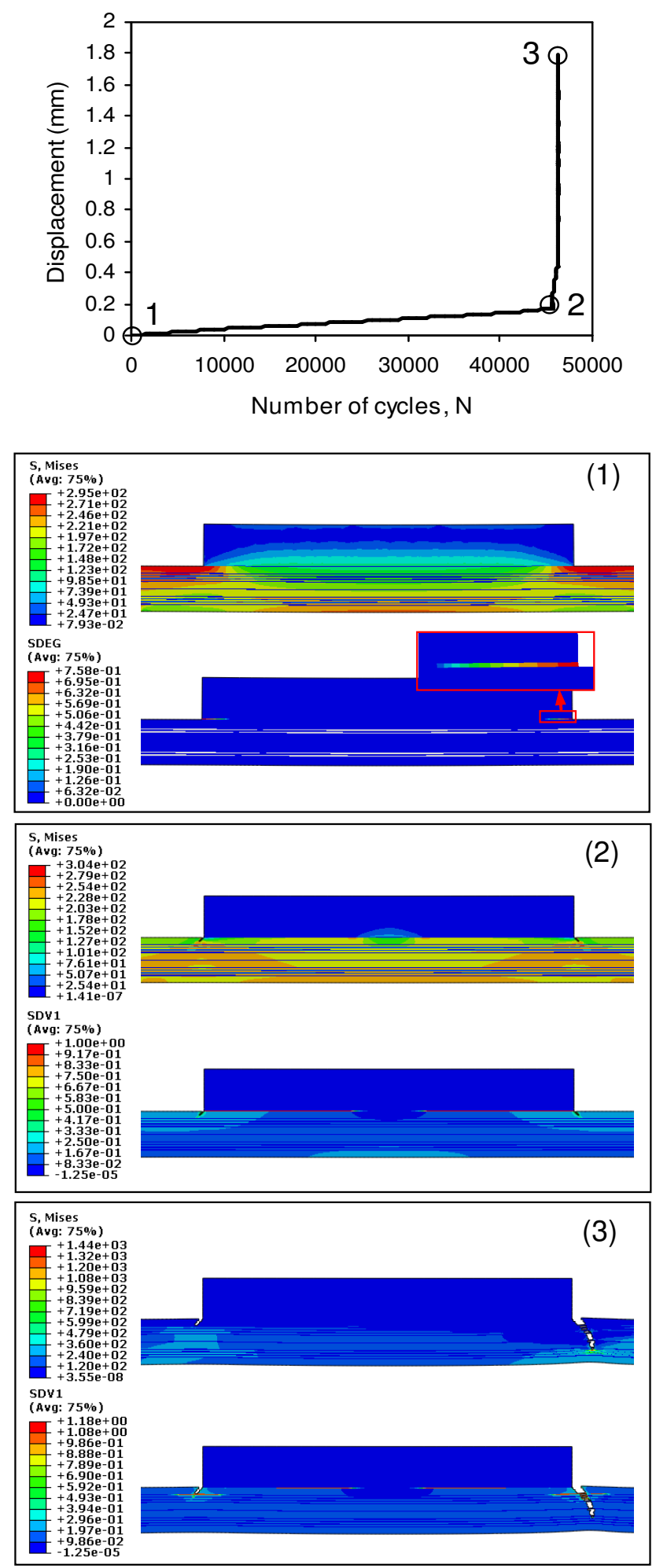

Fig. 15 The contour plots at the selected points of fatigue failure process of $\mathrm{CH}-\mathrm{NB}$ at load level of $60 \%$. 

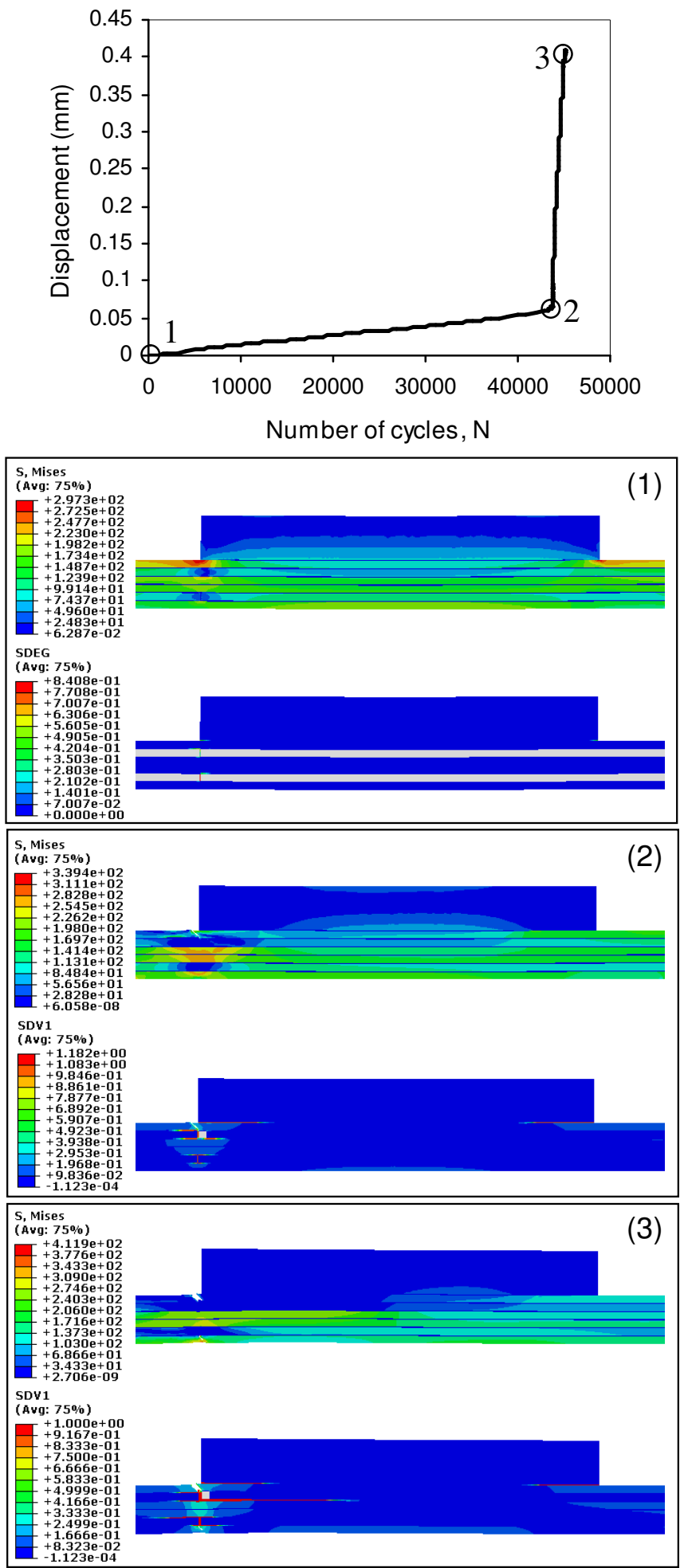

Fig. 16 The contour plots at the selected points of fatigue failure process of $\mathrm{CH}-\mathrm{B} 2$ at load level of $60 \%$. 


\section{List of Tables}

Table 1. The elastic properties of Al 2024-T3 and adhesive FM73.

Table 2. Plasticity data for Al 2024-T3 [41].

Table 3. Cohesive zone properties of FM 73.

Table 4. Mechanical properties of GFRP S2 glass/FM 94 epoxy [44].

Table 5. The equivalent orthotropic properties of Glare [45].

Table 6. Plasticity data for Glare [46].

Table 7. The parameters for the aluminium and adhesive fatigue damage model. 
Table 1. The elastic properties of Al 2024-T3 and adhesive FM73.

\begin{tabular}{lcc}
\hline Materials & $\begin{array}{c}\text { Young Modulus, } E \\
(\mathrm{MPa})\end{array}$ & Poisson's ratio, $v$ \\
\hline Al 2024-T3 & & \\
- Longitudinal $^{\mathrm{a}}$ & 70,000 & 0.33 \\
- Transverse $^{\text {FM73 }}$ & 70,000 & 0.33 \\
\hline
\end{tabular}

${ }^{\mathrm{a}}$ Reference [41]

${ }^{\mathrm{b}}$ Reference [42]

Table 2. Plasticity data for Al 2024-T3 [41].

\begin{tabular}{cccc}
\hline \multicolumn{2}{c}{ Longitudinal } & \multicolumn{2}{c}{ Transverse } \\
\hline $\begin{array}{c}\text { Yield stress } \\
(\mathrm{MPa})\end{array}$ & Plastic strain & $\begin{array}{c}\text { Yield stress } \\
(\mathrm{MPa})\end{array}$ & Plastic strain \\
\hline 300 & 0.000 & 290 & 0.000 \\
330 & 0.003 & 300 & 0.003 \\
370 & 0.015 & 340 & 0.011 \\
420 & 0.043 & 390 & 0.035 \\
440 & 0.100 & 430 & 0.100 \\
\hline
\end{tabular}

Table 3. Cohesive zone properties of FM 73.

\begin{tabular}{|c|c|c|c|c|c|c|c|c|}
\hline Material & $\begin{array}{c}E \\
(\mathrm{GPa})\end{array}$ & $\begin{array}{c}G \\
(\mathrm{GPa})\end{array}$ & $\begin{array}{c}G_{I} \\
(\mathrm{~N} / \mathrm{mm})\end{array}$ & $\begin{array}{c}G_{I I} \\
(\mathrm{~N} / \mathrm{mm})\end{array}$ & $\begin{array}{c}G_{I I I} \\
(\mathrm{~N} / \mathrm{mm})\end{array}$ & $\begin{array}{c}T_{n} \\
(\mathrm{MPa})\end{array}$ & $\begin{array}{c}T_{t} \\
(\mathrm{MPa})\end{array}$ & $\begin{array}{c}T_{s} \\
(\mathrm{MPa})\end{array}$ \\
\hline Cohesive in $\mathrm{ML}^{\mathrm{a}}$ & 2 & 0.75 & 2.5 & 5 & 5 & 53 & 30.5 & 30.5 \\
\hline $\begin{array}{l}\text { Cohesive-1 in } \\
\text { FML }^{\text {b }}\end{array}$ & 2 & 0.75 & 2 & 4 & 4 & 65 & 38 & 30 \\
\hline $\begin{array}{l}\text { Cohesive- } 2 \text { in } \\
\text { FML }\end{array}$ & 2 & 0.75 & 0.9 & 1.8 & 1.8 & 30 & 17 & 17 \\
\hline
\end{tabular}

Table 4. Mechanical properties of GFRP S2 glass/FM 94 epoxy [44].

\begin{tabular}{lcccccccc}
\hline \multicolumn{1}{c}{ Prepreg } & $\begin{array}{c}E \\
(\mathrm{GPa})\end{array}$ & $v$ & $\begin{array}{c}G \\
(\mathrm{GPa})\end{array}$ & $\begin{array}{c}G_{T}{ }^{*} \\
(\mathrm{~N} / \mathrm{mm})\end{array}$ & $\begin{array}{c}G_{C}{ }^{*} \\
(\mathrm{~N} / \mathrm{mm})\end{array}$ & $\begin{array}{c}\sigma_{T} \\
(\mathrm{MPa})\end{array}$ & $\begin{array}{c}\sigma_{C}(\mathrm{MP} \\
\mathrm{a})\end{array}$ & $\begin{array}{c}T \\
(\mathrm{MPa})\end{array}$ \\
\hline Longitudinal & 50 & 0.33 & 3.5 & 12 & 12 & 2000 & 550 & 93 \\
Transverse & 9 & 0.04 & 3 & 1 & 1 & 43 & 90 & 50 \\
\hline
\end{tabular}

$G_{T}=$ fracture energy in tension, $G_{C}=$ fracture energy in compressive

$\sigma_{T}=$ tensile strength, $\sigma_{C}=$ compressive strength, $T=$ shear strength

* Reference [24] 
Table 5. The equivalent orthotropic properties of Glare [45].

\begin{tabular}{ccccccccc}
\hline $\begin{array}{c}E_{1} \\
(\mathrm{GPa})\end{array}$ & $\begin{array}{c}E_{2} \\
(\mathrm{GPa})\end{array}$ & $\begin{array}{c}E_{3} \\
(\mathrm{GPa})\end{array}$ & $v_{12}$ & $v_{12}$ & $v_{23}$ & $\begin{array}{c}G_{12} \\
(\mathrm{GPa})\end{array}$ & $\begin{array}{c}G_{12} \\
(\mathrm{GPa})\end{array}$ & $\begin{array}{c}G_{23} \\
(\mathrm{GPa})\end{array}$ \\
\hline 60 & 45 & 22 & 0.33 & 0.33 & 0.24 & 8.5 & 8.5 & 7.5
\end{tabular}

$E=$ Young's Modulus, $v=$ Poison's ratio, $G=$ Shear modulus

Table 6. Plasticity data for Glare [46].

\begin{tabular}{lcccccc}
\hline Yield stress $(\mathrm{MPa})$ & 200 & 225 & 250 & 275 & 300 & 325 \\
\hline Plastic strain & 0 & 0.0025 & 0.005 & 0.0158 & 0.0258 & 0.0408 \\
\hline
\end{tabular}

Table 7. The parameters for the aluminium and adhesive fatigue damage model.

\begin{tabular}{lccc}
\hline \multicolumn{1}{c}{ Material type } & $\alpha$ & $\varepsilon_{t h}$ & $\beta$ \\
\hline Aluminium in ML and FML spanwise & 0.0186 & 0.0005 & 1.5 \\
Cohesive (FM 73M adhesive with mat & 0.025 & 0.0001 & 2.5 \\
carrier in ML) & & & \\
\hline $\begin{array}{l}\text { Aluminium in FML Chordwise } \\
\text { Cohesive (FM 73 adhesive with woven }\end{array}$ & 0.0372 & 0.0005 & 1.5 \\
carrier in FML) & 15 & 0.0004 & 2.5 \\
\hline GFRP & 400 & 0.0005 & 4 \\
\hline
\end{tabular}

